\title{
DEATH RELATED COSTS HYPOTHESIS IN THE CZECH HEALTH CARE SYSTEM - THE PRESENT AND THE FUTURE
}

\author{
Kateřina Pavloková*
}

\begin{abstract}
:
Growing concern about fiscal sustainability with respect to the population ageing has given rise to a large debate on the role of age in the context of health care expenditure. Growing evidence on the so called death related costs hypothesis arguing that the positive relationship between age of the cohort and related health care expenditure is the result of growing probability of death changes significantly influencing of the projections. The aim of this paper is to explore the importance of the death related costs hypothesis in the Czech health expenditure data and the impact of the hypothesis on the projection of the financial sustainability of the Czech health care system.
\end{abstract}

Keywords: health care, last year of life, fiscal sustainability.

JEL Classification: H51

\section{Introduction}

Growing concern about future sustainability of public health care systems has motivated numerous economists to simulate changes in future spending on health care related with population ageing. The ageing problem, which is the consequence of falling fertility rates coupled with increasing life expectancy, has become one of the important topics in numerous developed countries where the systems of pensions and health care are extremely vulnerable to demographic changes. The Czech Republic, whose pension system is based on the pay-as-you-go basis and whose health care system is financed from $86 \%$ from public spending (IHIS, 2008), is extremely sensitive to changes in demographic distribution of population. Yet the ageing problem is well visible in the Czech Republic as well. In 2050 the number of the 80+ in the Czech Republic is supposed to increase almost three times (Eurostat, 2008). After the baby-boom of the seventies the number of the new-born has decreased almost continuously. As

* Kateřina Pavloková, IES Faculty of Social Sciences, Charles University in Prague (katerina. pavlokova@gmail.com). The article was written with the support of the Round Table for the Future Path of Healthcare in the Czech Republic. The author wishes to thank Stanislav Vachek, Tomáš Roubal and Ondřej Matl for helpful comments.

The author also greatly appreciates the financial support of the Czech Science Foundation Grant No. 402/08/050 and the Institutional Support by the Department of Education MSMT 0021620841. Preliminary version of the paper was published in IES Working Paper Series as Pavloková, K. "Time to Death and Health Expenditure of the Czech Health Care System" IES Working Paper, No. 5/2009. IES FSV, Charles University. 
a consequence of this development, the most common age of a person living in the Czech Republic in 2050 will grow to more than seventy years (Eurostat, 2008).

Figure 1

Age Pyramids for the Czech Republic: 2007 and 2050

2007

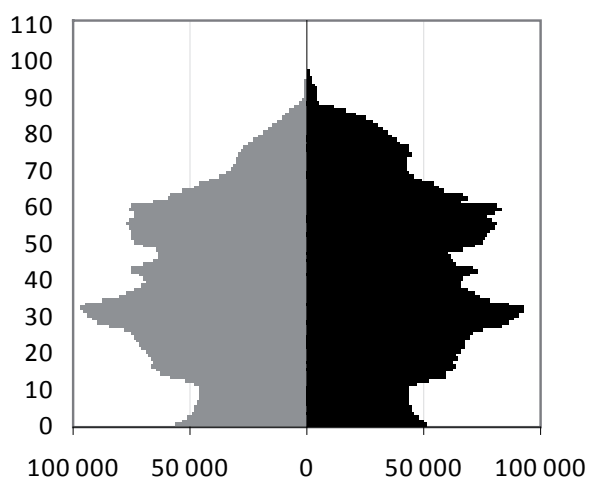

men women
2050

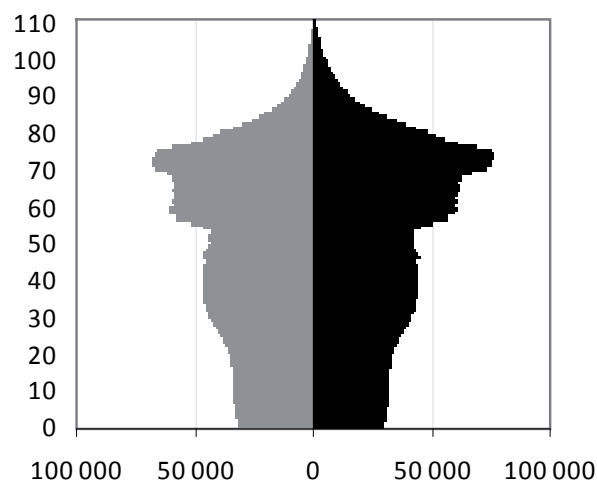

men women

Source: Czech Statistical Office (2008a) and population projection of Eurostat (2008)

The age pyramids (Figure 1) show an important change in the proportion of the elderly in the population. The most important age cohort in 2007 aged slightly above 30 years will be around 75 years old in 2050 shifting the average age of the population.

A quick look at an age related health care costs profile (Figure 2), which shows average annual health care expenditure $(\mathrm{HCE})^{1}$ by age categories, could easily lead to a conclusion that as health care costs are rising with age population ageing will lead to huge increases in health care spending in the future. We can see that the health care costs are higher in the childhood, then declining until the age of 22 (for women only until the age of 10), since that age growing almost exponentially until the age of 75-80 and then declining again.

1 List of abbreviations:

DRC Death related costs

GDP Gross domestic product

GLM Generalized linear models

HCE Health care expenditure

LTC Long-term care

IHIS Institute of Health Information and Statistics of the Czech Republic

OECD Organization for Economic Cooperation and Development

OLS Ordinary least squares

SHA System of health accounts

VZP ČR Všeobecná zdravotní pojišt’ovna České republiky (General Health Insurance Company of the Czech Republic) 
Figure 2

Age-Related Health Care Costs Profiles of Czech Men and Women, 2007

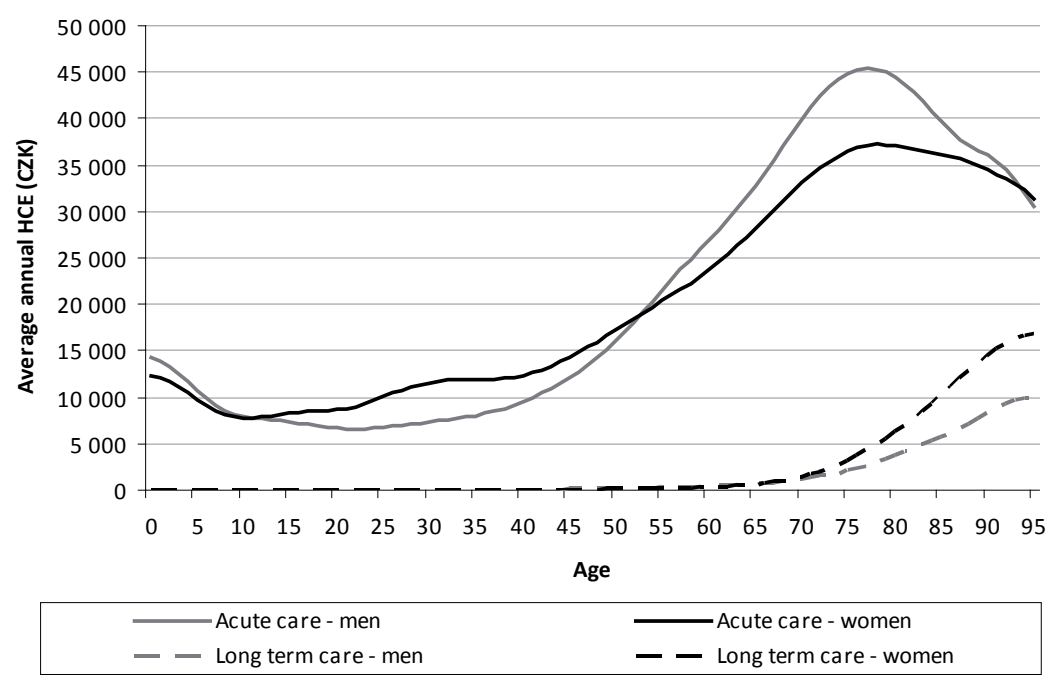

Source: Czech Statistical Office (2008b).

The relationship between the age of a cohort and related health care expenditures has been for a long time perceived as a causal relationship indicating the growth of need for the health care when the individual grows older. The death related costs Hypothesis has proposed an alternative explanation. When the individual grows older his probability of death is growing (as everybody has to die once). As the death of a person is usually accompanied by a costly attempt to save his/her life we might find a positive correlation between age and health care costs in the health care system as a whole. The so called death related costs Hypothesis according to which the health expenditure is concentrated in last years of life and according to which health expenditure is shifted to higher ages in line with the growth of life expectancy is thus based on high correlation between costly attempts to save the life of a person and the lack of success of the attempt - the case of death. We can thus presume that if the individual is dying his health care expenditures will probably grow.

The death related costs hypothesis has been tested in numerous studies all over the world by means of econometric methods. Zweifel, Felder and Meiers (1999) examined a hypothesis that "per capita health care expenditure is independent of population ageing" (p. 486). They used data about 6,000 and 8,000 deceased Swiss individuals from two major Swiss sickness funds respectively and they found insignificant effect of age on the health care costs for the individuals aged $65+$. In 2004 Seshamani and Gray found also a much bigger importance of the proximity of death then the effect of age. In a recent paper Werblow, Felder and Zweifel (2007) studied the effects of the death related costs in different components of health care expenditure. In the long-term care component they found a positive age effect nevertheless the conclusion of this paper states that "most components of health care expenditure are driven not by age but by closeness to death." (p.1125) 
The Ageing Working Group of the European Commission decided to include the death related costs effect in the projection of the health care costs of 2006, the OECD model of 2006 includes the death related costs effect as well. Unfortunately the lack of the data has been proven as an important problem for most of the health care costs projections. The exceptional quality of the databases of the Czech health insurance funds has enabled us to draw one of the most complex simulations of the effect of the death related costs that can be useful for all the countries where the data about the death related costs are not available. We hope that the Czech case could serve as a model situation for future health care costs simulations.

In the first part of the paper we test the death related costs hypothesis in the Czech data, in the second part we model the effect of the death related costs hypothesis on public health expenditure projection in the Czech Republic.

\section{The Death Related Costs Hypothesis in the Czech Data}

\subsection{Data}

We used the data on health care expenditures of the biggest Czech health insurance fund (General Health Insurance Company, VZP ČR) in 2004, the population included $6,990,901$ individuals. The population was restricted to individuals with positive or zero health expenditures (negative expenditures result from correction mechanisms within the fund), 35,433 observations were excluded from the population. The dataset finally included 6,955,468 individuals, 252,802 of them died within the following 3 years resulting in maximum time to death of the non survivors of 12 quarters of the year.

Unlike in other countries there are no deductibles in the Czech health care system. Moreover, most of the enrolees are registered to general practitioners that are paid by capitation payments resulting in nonzero expenditures for $99.33 \%$ of the enrolees. The age of the individuals is grouped into 18 five-year categories in line with the system of the redistribution of the premiums (i.e. the first category contains individuals aged 0 to 4 years, the second category contains individuals aged 5 to 9 years, etc., the last category contains individuals aged 85 and more).

Table 1

Descriptive Statistics

\begin{tabular}{|l|r|r|c|c|}
\hline & \multicolumn{2}{|c|}{ Deceased $(\mathrm{n}=252,802)$} & \multicolumn{2}{c|}{ Survivors $(\mathrm{n}=6,702,666)$} \\
\hline & Mean & \multicolumn{1}{c|}{ SD } & Mean & SD \\
\hline Share of women & 0.51 & 0.50 & 0.51 & 0.50 \\
\hline Age category (5 year categories, 1 to 18) & 14.89 & 2.69 & 8.48 & 4.36 \\
\hline Quarters to death (in quarters of year) & 6.39 & 3.48 & &. \\
\hline Long-term care (CZK) & 12142 & 42527 & 1800 & 12305 \\
\hline Pharmaceuticals (CZK) & 6569 & 20467 & 1553 & 6854 \\
\hline Acute care except pharmaceuticals (CZK) & 38154 & 107665 & 10500 & 45728 \\
\hline Total HCE (CZK) & 56865 & 126599 & 13854 & 50994 \\
\hline
\end{tabular}

Note: The average age category of the deceased corresponds to age 65-69 years, the average age category of survivors corresponds to age 35-39 years. 
The population thus included $51 \%$ of women with average age category corresponding to 65-69 years for dying individuals and to 35-39 years for survivors. The dying individuals were on average 1.6 year far from death.

Average HCE in 2004 was four times higher for those who were going to die within the following three years, for long term care even 6.7 times higher (Table 1).

The box-plot (Figure 3) can best illustrate the variance of the health care costs for survivors and the deceased. For reason of better visibility the health expenditure on the figure has been transformed by a logarithmic transformation as the health expenditure data follow approximately the log-normal distribution. Nevertheless the conclusions that may be drawn from the figure are valid for health expenditure as well. In the box-plot the bottom of the box shows the first quartile of the observed variable (log of total health expenditure), the line inside the box shows the median and the top of the box shows the third quartile. The outliers are defined as observations that are by more then 1.5 the inter-quartile range far from the box. The category 0 shows all the individuals in the sample that did not die. Other numbers show time to death in quarters of the year.

Figure 3

Box-Plot of the Log HCE in 2004

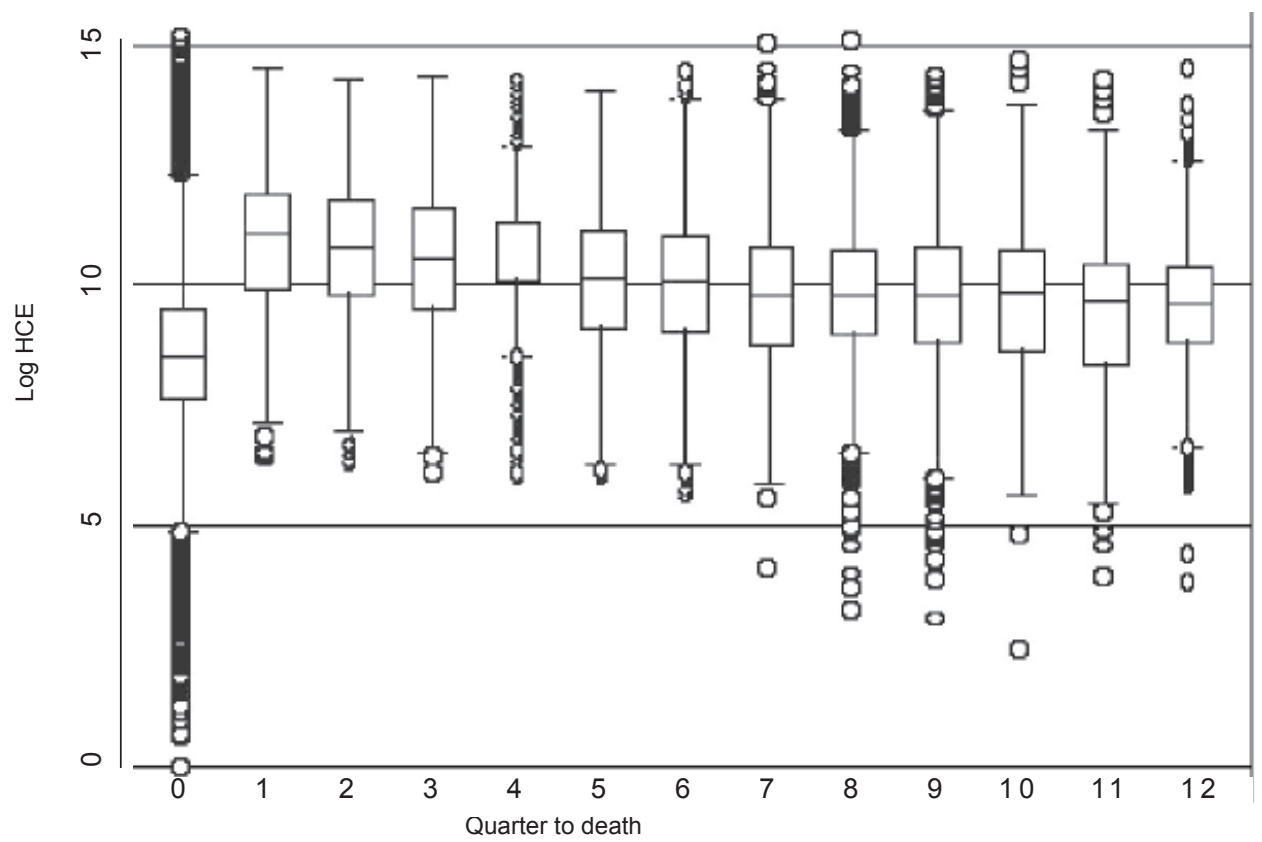

Source: General Health Insurance Company (VZP ČR) database, own calculation.

We can see that the median as well as the first and third quartiles of the log HCE are higher for the deceased, however, the highest outliers can be found in the survivor's category as the variance of health care costs is highest in this category. The results do not contradict the death related costs hypothesis in the Czech data. 


\subsection{Methods}

We do not use the two part model consisting of probit and OLS models that has become a standard in the death related costs studies (see Werblow, Felder, Zweifel, 2007 and others) as we do not face the problem of the sample selection bias. The sample selection bias occurs when a large part of the population has zero health expenditure from the point of view of the health insurance fund in the examined time period and the analysis using data on health expenditure risks to examine a non-representative sample of the population by over-representing the sick enrolees (Seshamani, Gray, 2004). Such a situation arises for example in health systems where deductibles are paid or in health systems with high co-payments. The Czech health care system where the enrolees do not pay any deductible and where $92.5 \%$ of the population is registered to general practitioners paid by capitation schemes (IHIS, 2008) having thus minimum annual expenditure of CZK 396 does not face the problem of the lack of the data on health expenditure.

In line with Werblow, Felder and Zweifel (2007) we use two methods of parameter estimates: the ordinary least squares method (OLS) with white robust standard errors and alternatively the generalized linear model (GLM) with family gamma and logarithmic link.

The problem of the linear models such as the OLS in the context of the health expenditures data that are highly skewed to the right and heteroscedastic has been largely discussed in the literature. The use of the log transformation of the HCE data that have approximately lognormal distribution is connected with the problem of retransformation (when the parameter estimates from the log-transformed model are recalculated for the HCE that we usually need the new parameter estimates may be biased when data are heteroscedastic), however, OLS without transformation suffers from lack of robustness (the OLS is not best unbiased estimator when the condition of normal distribution of errors is not satisfied). Nevertheless according to Lumley, Diehr, Emerson and Chen (2002) the use of the OLS without transformation is justifiable in large public health data sets although the normality condition is not satisfied.

The GLM with family gamma, fitted by maximum likelihood, that is used as an alternative to the log-transformed OLS model does not face the problem of retransformation as the mean and variance functions are based on the original (not transformed) data and the relationship between them is defined by the link function. Actually when analyzing the log-transformed data by the OLS method one assumes that the mean of these new observations is linearly explained by the covariates. The analysis with a gamma GLM retains the original observations and a log-transformation of the mean of the original observations is explained linearly by the covariates. (Halekoh and Hojsgaard, 2007) However, the parameter estimates obtained by GLM method can be less precise (Deb, Manning, Norton, 2006).

For both methods, the dependent variable is total HCE in 2004 in CZK reported by the insurance fund. For the explanatory variables we use the set of dummy variables for the age categories, sex ( 1 for women and 0 for men) and quarters to death up to the number of 12. Both survivors and deceased are included in the estimation. In the following equations $j$ describes the age category and $l$ time to death in quarters of year for individual $i$. 
For OLS we estimate the following equation:

$$
E\left(H C E_{i}\right)=\alpha+\beta . \operatorname{sex}_{i}+\sum_{j=1}^{18} \chi_{j} \text { age category }_{i, j}+\sum_{j=1}^{12} \delta_{l} \text { quarter to death }_{i, l}, \text { (1) }
$$

where $H C E_{i} \sim N\left(\mu_{i}, \sigma^{2}\right)$

The GLM may be described by the following equation:

$$
\log (E(H C E i))=\alpha+\beta . \operatorname{sex}_{i}+\sum_{j=1}^{18} \chi_{j} \text { age category }_{i, j}+\sum_{j=1}^{12} \delta_{l} \text { quarter to death }_{i, l},
$$

where $H C E_{i} \sim \operatorname{Gamma}\left(\mu_{i} \mid a, a\right)$, where $a$ represents the common shape of means and variances.

\subsection{Results}

We found significant effects of both age and death in both specifications; the effect of death is more pronounced than age. The $\mathrm{R}^{2}$ of the OLS model is low but standard in health care costs analysis using demographic variables mostly. Based on the results we cannot reject the DRC hypothesis in the Czech data.

Table 2

\begin{tabular}{|c|c|c|c|c|}
\hline & \multicolumn{2}{|c|}{ glm HCE } & \multicolumn{2}{|c|}{ OLS HCE } \\
\hline & Coef. & Std. Err. & Coef. & Std. Err. \\
\hline sex & $0.101^{* *}$ & 0.005 & $316^{* *}$ & 33 \\
\hline age1 & $-1.015^{* *}$ & 0.022 & $-19324^{* *}$ & 164 \\
\hline age2 & $-1.499^{* *}$ & 0.022 & $-23328^{* *}$ & 152 \\
\hline age 3 & $-1.438^{* *}$ & 0.021 & $-22860^{* *}$ & 153 \\
\hline age4 & $-1.514^{* *}$ & 0.021 & $-23365^{\star *}$ & 152 \\
\hline age5 & $-1.509^{* *}$ & 0.02 & $-23382^{* *}$ & 151 \\
\hline age6 & $-1.239^{* *}$ & 0.02 & $-21273^{* *}$ & 153 \\
\hline age 7 & $-1.386^{\star \star}$ & 0.02 & $-22357^{\star *}$ & 152 \\
\hline age8 & $-1.226^{\star *}$ & 0.02 & $-21308^{* *}$ & 154 \\
\hline age9 & $-0.957^{\star *}$ & 0.02 & $-18514^{* *}$ & 163 \\
\hline age10 & $-0.646^{\star *}$ & 0.02 & $-14609^{* *}$ & 174 \\
\hline age11 & $-0.676^{* *}$ & 0.02 & $-14819^{* *}$ & 157 \\
\hline age12 & $-0.295^{\star *}$ & 0.02 & $-7830^{* *}$ & 166 \\
\hline age13 & $-0.257^{* *}$ & 0.02 & $-6579^{* *}$ & 168 \\
\hline age14 & -0.001 & 0.021 & $664^{* *}$ & 193 \\
\hline age15 & $-0.07^{* *}$ & 0.021 & $-1841^{* *}$ & 170 \\
\hline age16 & -0.008 & 0.022 & -227 & 175 \\
\hline age18 & $-0.287^{* *}$ & 0.035 & $-9396^{* *}$ & 230 \\
\hline 1 quarter to death & $1.666^{\star \star}$ & 0.29 & $109776^{* *}$ & 8755 \\
\hline
\end{tabular}

Estimation Results 


\begin{tabular}{|c|c|c|c|c|}
\hline 2 quarters to death & $2.073^{* *}$ & 0.271 & $103777^{* *}$ & 10990 \\
\hline 3 quarters to death & $1.481^{* *}$ & 0.226 & $69765^{\star *}$ & 6447 \\
\hline 4 quarters to death & $1.571^{* *}$ & 0.163 & $61075^{\star \star}$ & 2890 \\
\hline 5 quarters to death & $1.053^{* *}$ & 0.144 & $41866^{\star *}$ & 2618 \\
\hline 6 quarters to death & $1.126^{\star *}$ & 0.124 & $42875^{\star *}$ & 2633 \\
\hline 7 quarters to death & $0.908^{* *}$ & 0.095 & $31154^{* *}$ & 1816 \\
\hline 8 quarters to death & $0.778^{* *}$ & 0.075 & $25269^{* *}$ & 1207 \\
\hline 9 quarters to death & $0.697^{* \star}$ & 0.045 & $22943^{* *}$ & 591 \\
\hline 10 quarters to death & $0.301^{* *}$ & 0.048 & $8445^{* *}$ & 424 \\
\hline 11 quarters to death & $0.218^{* *}$ & 0.047 & $5792^{* *}$ & 401 \\
\hline 12 quarters to death & $0.732^{* *}$ & 0.044 & $26000^{* *}$ & 923 \\
\hline _cons & $10.259^{* *}$ & 0.018 & $29833^{* *}$ & 149 \\
\hline $\mathbf{R}^{2}$ & & & 0.0464 & \\
\hline AIC & 20.1496 & & & \\
\hline BIC & $-1.75 e+07$ & & & \\
\hline $\begin{array}{l}\text { number of } \\
\text { observations }\end{array}$ & $1408528^{1}$ & & 6955468 & \\
\hline
\end{tabular}

** Significant at the $1 \%$ significance level

Note: The parameter estimates of the GLM specification are not directly comparable to the OLS estimates as the method uses the logarithmic link. The estimates would be comparable to the log-transformed OLS.

1/ A random sample from the population created by Stata was used for the technical reasons (computer capacity) for the GLM specification.

\section{Projection of the Health Care System Financial Sustainability}

\subsection{Data}

We use the costs profiles reported by all the health insurance funds to the Czech Statistical Office in 2006 which are collected mainly for the aim of the redistribution of the premiums between the insurance funds. The data make part of the System of Health Accounts database (Czech Statistical Office, 2008b). The data are in the structure of five-year categories. For the use of the projection they were smoothed by the kernel regression with Gaussian kernel to one-year categories as the model needs to work with one-year age categories (the death related costs in the model are defined as costs one year prior to death).

The costs profiles of the deceased individuals in 2006 were collected from the biggest health insurance fund in the Czech Republic (VZP ČR) reporting the multiple of the average costs of the deceased individuals based on the average costs in every five year category. The costs profile of the deceased individuals was smoothed by the means of the kernel regression as well for reason described above.

The demographic projection used in the model is the no-migration scenario of the demographic projection of Eurostat for the Czech Republic (Eurostat, 2008). The demographic projection reports numbers of men and women in one year age categories in every year since 2050. The number of the deceased individuals in age category $j$ in 
year $t$ was computed as the difference between the number of individuals in the age category $j$ in year $t$ and the number of individuals in age category $j-1$ in the previous year $(t-1)$.

The demographic projection by Eurostat ends in the category of $80+$. We lengthened the prediction until 110 as the computation of life expectancy needed in the model requires to set the life expectancy in the last age category to 0 which would not be true for the 80 years old individuals. We used the exponential shape of the decrease in the number of surviving individuals.

\subsection{The baseline scenario}

As the baseline scenario we use the pure ageing scenario methodology used by the European Commission (2006). The basic simulation of the future health care spending starts with an age related health care costs profile that is applied to the demographic prediction of the population. The average health care costs for an individual of age $j$ and sex $k$ in 2006 are multiplied by the number of individuals of age $j$ and sex $k$ in every year of the demographic projection. The spending in a particular year without taking into account the growing unit costs can be described by the following equation:

$$
\cos t s_{t}=\sum_{j=1}^{110} \sum_{k=1}^{2} c_{j, k} \cdot \text { pop }_{j, k, t}
$$

where $c_{j, k}$ are the costs per capita for each age and sex category that are given by the initial year of the prediction - year 2006 and where the $p o p_{j, k, t}$ stands for number of the individuals in defined age and sex categories in year $t$ given by the demographic prediction. We take the assumption of the unit costs growth equal to the GDP per capita growth. This assumption can be thought as the real price stability of the health care sector and is used both in the European Commission (2006) and the OECD (2006). The costs computed by multiplying the average costs for each age and sex category by the number of the individuals in those categories for every year are multiplied by the share of the GDP per capita in every single year to the initial GDP per capita. The final health care costs can thus be described by the following equation:

$$
\cos t \text { in } \text { current prices }_{t}=\cos t s_{t} \cdot \frac{G D P \text { per capita in current prices }}{\text { GDP per capita in current prices } \text { cun }_{t=0}}
$$

We use the long term macroeconomic prediction of the Ministry of Finance ${ }^{2}$ for the prediction of future participation rate on the labour market (i.e. the proportion of economically active individuals to total population) for every age category and every year of the projection, GDP deflator and labour productivity growth (Ministry of Finance, 2008). The GDP in the model is growing at the rate of the change in the labour productivity multiplied by the number of workers. We thus do not model any change in the capital-labour ratio. We can describe the method by the following equations:

2 The prediction was kindly prepared by Ing. Vít Pošta, Ph.D., Ing. Zbyněk Štork and Ing. Zdeněk Veselý from the Ministry of Finance for the use of the Round Table for the Future Path of Healthcare in the Czech Republic. 


$$
\left.\operatorname{prod}_{t-1} \cdot\left(1-u_{t-1}\right) \cdot \sum_{i=1}^{110} \sum_{j=1}^{2} \operatorname{pop}_{j, k, t-1} \cdot \text { participation rate }_{j, k, t-1}\right)
$$

where for every year the GDP stands for GDP in constant prices, prod stands for productivity, $u_{t}$ for unemployment rate and ${ } o p_{j, k, t}$ for the number of individuals of age $j$ and sex $k$ in the demographic prediction.

State and local budgets expenditure that is not age related such as investment in hospitals and other, which represented $11.7 \%$ of public health expenditure (IHIS, 2008 ) in 2006, is growing at the GDP per capita rate.

\subsection{The Death Related Costs Scenario}

For the death related costs scenario we divide the population more than we did in the baseline scenario. We use four health care costs profiles: surviving males, surviving females, deceasing males and deceasing females. The difference between the age related health care costs profiles is shown in the Figure 4.

Figure 4

The Age Related Health Care Costs Profiles, Survivors and Deceased (acute care, men, 2007)

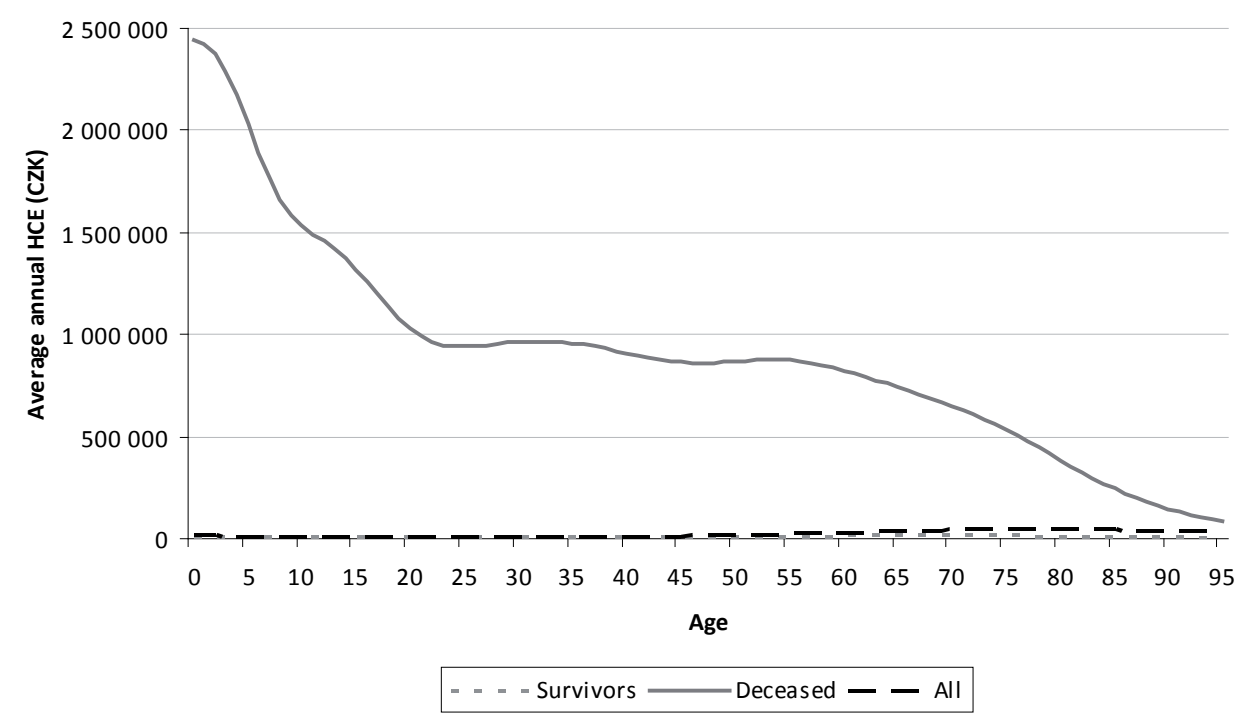

Source: VZP ČR database and Czech Statistical Office (2008b), own calculation.

For children, the average annual health expenditure of dying individuals is as much as 200 times higher than the HCE of the survivors reaching almost 2.5 million Czech korunas a year. As the age grows, the difference between dying individuals 
and survivors as well as the HCE of the dying individuals itself falls. The average $\mathrm{HCE}$ of all the population approaches the HCE of survivors for young ages as only few individuals die in young age. For the elderly, the average HCE of all the population gets closer to the HCE of the dying individuals as the proportion of dying individuals grows.

The question we may ask observing the Figure 4 is why the average HCE of the dying individuals falls with age. There are at least two possible explanations. First of all, the HCE of the deceasing individuals are related to the diagnosis individuals are dying at in different ages (Figure 5). The health care costs are very high for children dying mostly because of congenital defects. Between the age of 20 to 40 years individuals die mostly because of external causes including accidents and others that require also high $\mathrm{HCE}$. The bulk of costs at the age of 65 is related to the bulk of cancers at that age that are also costly. After the age of 65 the main diagnosis of death is gradually becoming the cardiovascular diseases for which the costs in the last year of life are lower.

Figure 5

Main Causes of Death in the Czech Republic (2005)
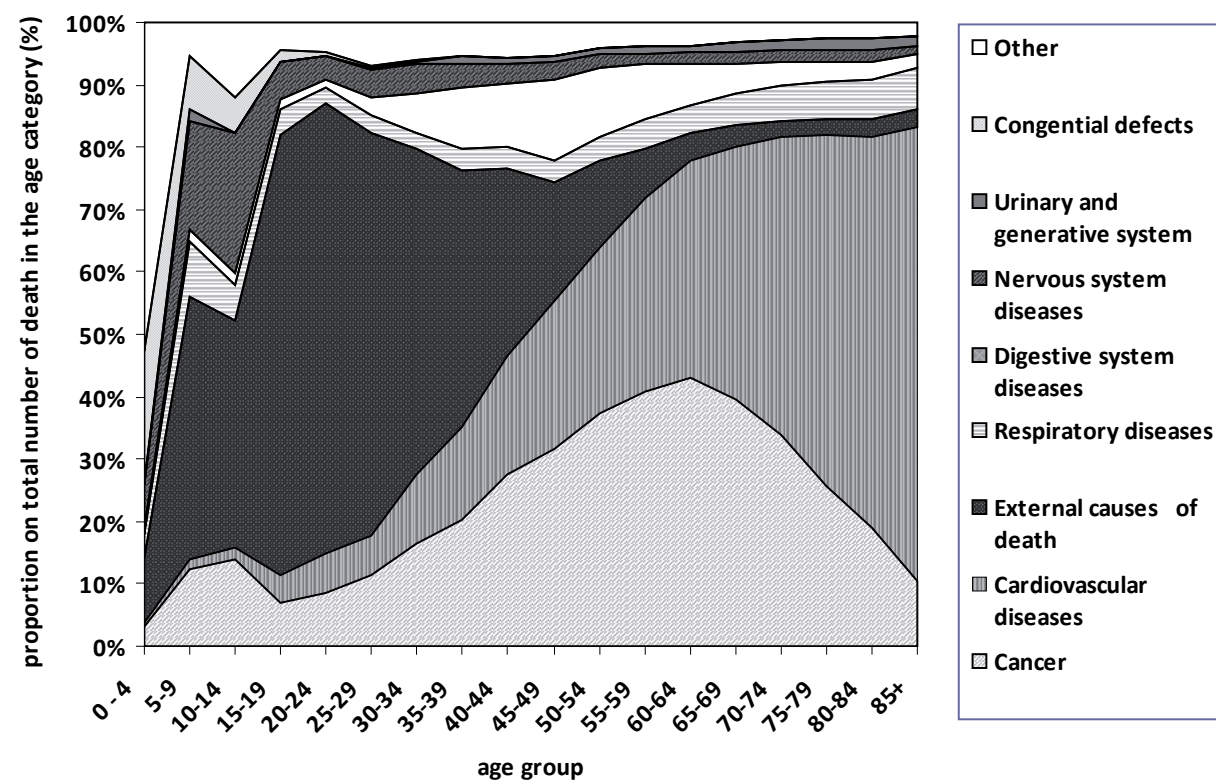

Source: Czech Statistical Office 2008c.

The second explanation relates to higher motivation for saving the life of children and young individuals as the society is willing to invest more resources in individuals that could live for longer period. The motivation for saving the life of the elderly is dropping off with age as the life expectancy falls.

The construction of the scenario is similar to the basic scenario with the difference that more health care costs profiles are taken into account. We added the costs profiles of the deceased males and females. We can describe the model by the following equation and then equation (3): 


$$
\cos t s_{t}=\sum_{j=1}^{110} \sum_{k=1}^{2} \sum_{l=0}^{1} c_{j, k, l} \cdot \operatorname{pop}_{j, k, l, t}
$$

where the $c_{j, k, l}$ states for the costs per capita for an individual of age $j$, sex $k$ and the status of a deceased person: $l=0$ for survivors, $l=1$ for the deceased in the year $t$. The $c_{j, k, l}$ are given by the initial year 2006.

\subsection{The Health Status of the Population}

Until now, we assumed that the age related health care costs profiles would remain stable over time irrespective of the demographic changes such as growth of the life expectancy. However, this assumption implies the so called "expansion of morbidity" hypothesis that has been proposed in 1977 by Grunenberg as we do not take into account possible improvements in the health status of the population. According to the above mentioned hypothesis, the number of years of life spent in good health will remain constant and all the additional years of life gained by the growth of the life expectancy will be spent in bad health due to chronic illnesses. Assuming stable age related health care costs profiles means that an individual aged 60 years in the last year of the projection will enjoy the same health status as an individual aged 60 years in the initial year of the projection. With increasing life expectancy, the proportion of life where higher health expenditure occurs thus grows.

However, the literature has proposed much more optimistic scenarios. According to the "compression of morbidity" hypothesis proposed by Fries in 1980, the growing life expectancy will be accompanied by improvements in the health status of the population. Even more than additional years of life gained by the growth of life expectancy will be spent in good health thanks to improvements in the lifestyle, better prevention of illnesses and other reasons. For example, an individual aged 60 years in the last year of the projection would enjoy the same health status as an individual aged only 50 years in the initial year of the projection.

A compromise between the two hypotheses has been known in the literature as the "dynamic equilibrium" scenario. In the scenario, additional years of life are translated one to one into the years spent in good health. The scenario has been described by Manton in 1982.

The European Commission has proposed a methodology how to model the three hypotheses about the health status of the population in health care expenditure projections. The hypothesis about the health status of the population are translated into the age related health care costs profiles which are shifted to higher ages in line with increases of the life expectancy. When translating the hypothesis into the age related health care costs profiles, the methodology assumes that the health status of an individual is directly related to his health care costs (i.e. healthier means less costly).

In the so called "pure ageing scenario", modelling the expansion of morbidity hypothesis, the age related health care costs profiles remain stable over time as we have already mentioned and described above.

In the so called "constant health scenario", that represents the dynamic equilibrium hypothesis where exactly the additional years of life are lived in good health, the age related health care costs profiles are shifted to higher age (i.e. on the right) by exactly the change in life expectancy. 
In the "improved health scenario", people care more about their health status and the technological progress enables them to gain two times more years in good health than the years gained by the growing life expectancy (i.e. the compression of morbidity hypothesis). The age related costs profiles are shifted by two times the change in life expectancy.

Technically, for every year we obtain the change in life expectancy by subtracting the life expectancy of the year 2006 from the life expectancy in year $t$ for an individual of age $k$ and $\operatorname{sex} j$ :

$$
\Delta e_{j, k, t}=e_{j, k, t}-e_{j, k, 2006}
$$

where $e_{j, k, t}$ stands for life expectancy for an individual of age $j$ and sex $k$ in year $t$. The costs per capita of an individual aged $j$ in the year $t$ are calculated as costs of an individual aged $j$ minus the change in life expectancy (or minus two times the change in life expectancy for improved health scenario) in the initial year of the projection. The method can be described by the following formulas:

The constant health scenario: (9)

The improved health scenario: (10)

$$
\begin{aligned}
c_{j, k, t} & =c_{j-\Delta e_{j, k, t}, k, 2006} \\
c_{j, k, t} & =c_{j-2 \Delta e_{j, k, t}, k, 2006}
\end{aligned}
$$

The costs per capita thus follow the biological age of the person, not the actual age. We do not shift the costs profile as a whole because there is no reason to assume that the costs of care for children would follow the biological age and remain higher for longer part of the life than they are now. We shift the costs profile from the point of the minimum average costs (approximately age 30 for men, less for women) (Figure 6).

Figure 6

The Shift of the Health Care Costs Profile (acute care, men, survivors, year 2050)

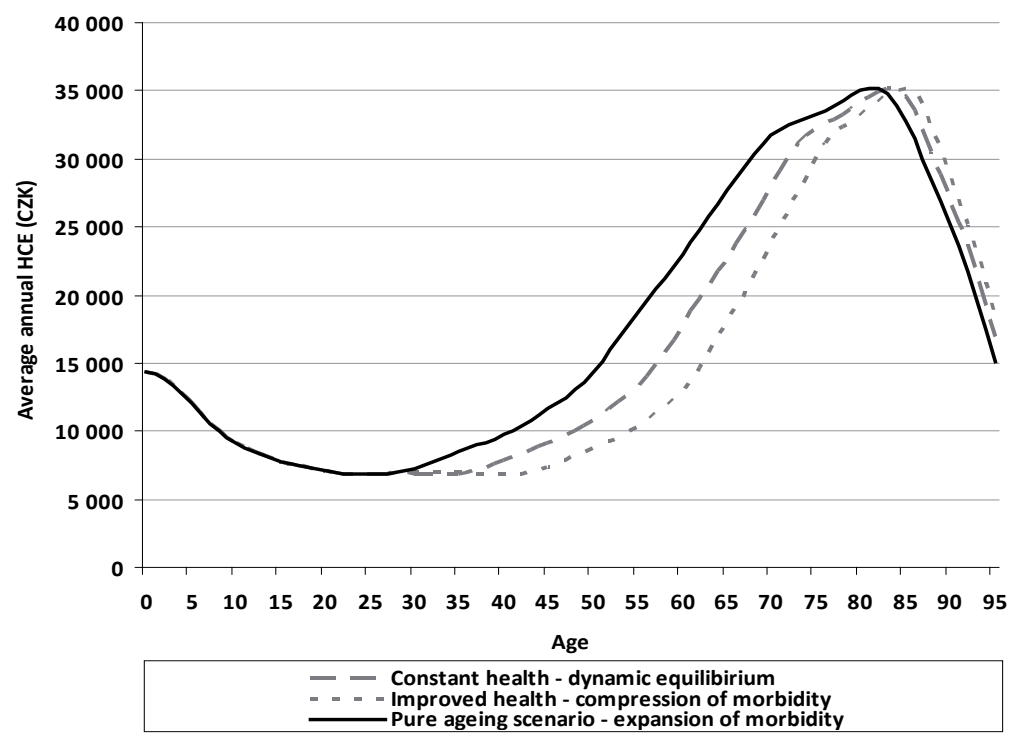

Source: System of health accounts, own calculation. 
The age related health care costs profile of the pure ageing scenario is exactly the one of the initial year of the projection. The other two costs profiles show the shift related to the improvement in the health status of the individual. As the growth of the life expectancy of an individual aged 60 years in 2050 with respect to the initial year of the projection has been approximately 6 years, the costs profile is shifted on the right by 6 years for the constant health scenario and by 12 years for the improved health scenario. The HCE of an individual aged 60 years in 2050 thus corresponds to the HCE of an individual aged 60 years for the pure ageing scenario, 54 years for the constant health scenario and 48 years for the improved health scenario.

The total costs and the share of costs on GDP are then calculated using the same methodology as we have already described in the preceding sections.

For the death related costs scenario we do not shift the costs profiles of the deceased individuals.

As a result, six scenarios of the future path of total public health expenditure have been modelled. These scenarios are the pure ageing scenario without taking into account the DRC hypothesis (the baseline scenario), the pure ageing scenario taking into account the DRC hypothesis, the constant health scenario without DRC hypothesis, the constant health scenario with DRC, the improved health scenario without DRC hypothesis and finally the improved health scenario with DRC hypothesis.

\section{Results}

The resulting total health expenditure of the public health care system in the Czech Republic in percentage of GDP for the initial year of the projection, for year 2025 and for year 2050 according to the different scenarios are summarized in Table 3:

Table 3

Projection Results, Total Public Health Rxpenditure in percentage of GDP

\begin{tabular}{|l|c|c|c|}
\hline & $\mathbf{2 0 0 6}$ & $\mathbf{2 0 2 5}$ & $\mathbf{2 0 5 0}$ \\
\hline Pure ageing & $6.19 \%$ & $7.23 \%$ & $8.87 \%$ \\
\hline Pure ageing with death related costs & $6.19 \%$ & $6.87 \%$ & $7.60 \%$ \\
\hline Constant health & $6.19 \%$ & $6.88 \%$ & $8.09 \%$ \\
\hline Constant health with death related costs & $6.19 \%$ & $6.59 \%$ & $7.04 \%$ \\
\hline Improved health & $6.19 \%$ & $6.57 \%$ & $7.44 \%$ \\
\hline Improved health with death related costs & $6.19 \%$ & $6.34 \%$ & $6.55 \%$ \\
\hline
\end{tabular}

In the pure ageing scenario without death related costs, the total public HCE would increase between years 2006 and 2050 by $43 \%$ and would reach in $20508.87 \%$ of GDP. Such an increase could cause important imbalances in the financing of healthcare in the Czech Republic if the revenues of the public health care system in percentage of GDP did not increase. However, when the death related costs hypothesis, supported by the econometric part of our analysis, is taken into account the increase of the total public HCE is reduced to $23 \%$ and total public HCE would reach only $7.6 \%$ of GDP. If moreover we take into account the hypothesis 
about the improvement of the health status of the population, namely the improved health scenario with DRC, we end with an increase by only $5.8 \%$ (i.e. the total public HCE would reach only $6.55 \%$ of GDP) (Table 3 ).

The time path of the scenarios is shown in Figure 7.

Figure 7

Expenditure of the Czech Public Health Care System (\% GDP)

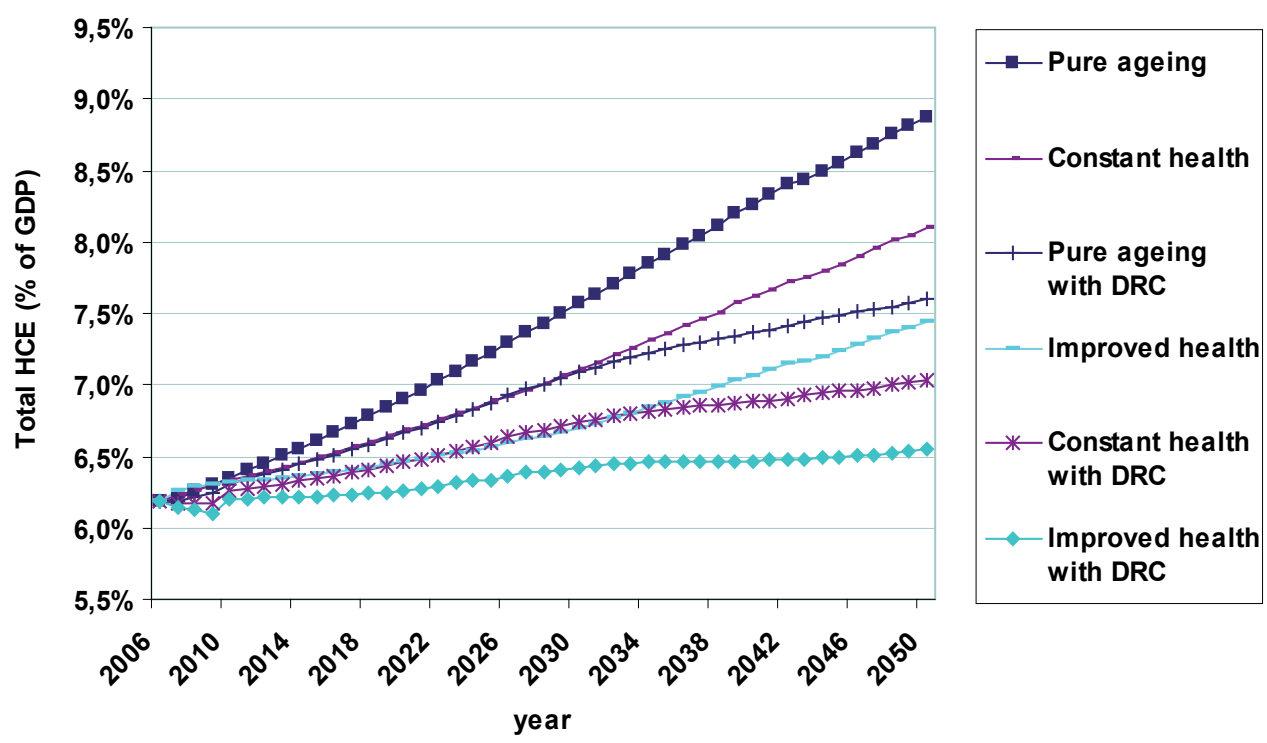

The time path of the different scenarios shows important differences resulting from the use of the alternative hypotheses about the evolution of the health status of the population and from the importance we award to the DRC hypothesis. In this place, we have to emphasize that the model does not have the ambition to predict reality but that it only shows the incidence of alternative hypothesis concerning health care costs described in the literature.

\section{Conclusion}

The factor of death proved to be significant for health care expenditure in the Czech Republic by both GLM and OLS methods. Including the death related costs effect according to which health expenditure is postponed to higher age in line with the postponement of death in the projections of future health care spending changes in an important manner the results of the projections. If moreover the compression of morbidity hypothesis is taken into account almost no change of health care expenditure is projected in relation with the ageing of the population. Yet these optimistic scenarios are not supported by current trends in health care spending in most of the developed world where the trend of health care expenditure is definitely increasing. The conclusion that we can draw from these facts is either that other factors than population ageing are important for health expenditure (factors such as technological progress or growing 
expectations of individuals) or that the optimistic expectations of compression of morbidity and postponement of health care costs in line with postponement of death are not realistic.

\section{References}

Czech Statistical Office (2008a), "Age Distribution of the Population 2007." [online] http://www.czso. cz/csu/2008edicniplan.nsf/engpubl/4003-08-2007.

Czech Statistical Office (2008b), System of Health Accounts database.

Czech Statistical Office (2008c): "Zemřelí podle podrobného seznamu př́čin smrti, pohlaví a věku v ČR a v krajích (1994 až 2007)." [online] http://czso.cz/csu/2008edicniplan.nsf/ kapitola/4017-08-(1994_az_2007)-2005.

Deb, P., Manning, W., Norton, E. (2006), "Modeling Health Care Costs and Counts", ASHE - Madison Conference, 2006. [online] http://www.unc.edu/ enorton/DebManningNortonPresentation.pdf.

European Commission (2005), "Factors Driving Public Expenditure on Health Care over the Long-Term and an Overview of Methodologies Used to Make Expenditure Projections." ECFIN/C/5/ BP D(2005), REP/51821, Brussels.

European Commission (2006), "The Impact of Ageing on Public Expenditure: Projections for the EU25 Member States on Pensions, Health Care, Long-Term Care, Education and Unemployment Transfers (2004-2050)." Special Report No. 1/2006.

EUROSTAT (2008), "Population Projection." [online] http://epp.eurostat.ec.europa.eu/extraction/ evalight/EVAlight.jsp?A=1\&language=en\&root=/theme3/proj/proj_tbp_pop.

Fries, J. F. (1980), "Ageing, Natural Death, and the Compression of Morbidity." New England Journal of Medicine 303: pp. 130-135.

Grunenberg, E. M. (1977), "The Failure of Success." Milbank Memorial Fund Quarterly Health Soc. 55: pp. 3-24.

Halekoh, U., Hojsgaard, S. (2007), "GLM - Gamma distributed data." [lecture, online] http://gbi.agrsci. $\mathrm{dk} /$ statistics/courses/phd07/misc/learn/modules/GIm/build/gamma/pdf/lecture-slide.pdf.

IHIS (2008), "Czech Health Statistics Yearbook 2007." [online] http://www.uzis.cz/download.php?ctg= 10\&search_name $=$ Czech\%20health\%20statistics\%20yearbook\&region=100\&mnu_id $=5300$.

Lumley, T., Diehr, P., Emerson, S., Chen, L. (2002), "The Importance of the Normality Assumption in Large Public Health Data Sets." Annual Revue of Public Health, No. 23, pp.151-169.

Manton, K. G. (1982), "Changing Concepts of Morbidity and Mortality in the Elderly Population." Milbank Memorial Fund Quarterly Health Soc. 60(2): pp. 183-244.

Ministry of Finance (2008), "Macroeconomic Prediction of the Czech Republic," Round Table Project for the Future Path of Healthcare in the Czech RepublicOECD (2006), "Projecting OECD Health and Long-Term Care Expenditures: What Are the Main Drivers." ECO/WKP(2006)5.

Seshamani, M. (2004), "The Impact of Ageing on Health Care Expenditures: Impending Crisis, or Misguided Concern?" Office of Health Economics, York University, York.

Seshamani, M., Gray, A. (2004), "Ageing and Health Care Expenditure: The Red Herring Argument Revisited", Health Economics, Vol. 13, No. 4.

Werblow, A., Felder, S., Zweifel, P. (2007), "Population Ageing and Health Care Expenditure: a School of 'Red Herrings'? Health Economics No. 16, pp. 1109-1126.

Zweifel, P., Felder, S., Meiers, M. (1999), "Ageing of Population and Health Care Expenditure: A Red Herring?" Health Economics, Vol. 8, No. 6.

Zweifel, P., Felder, S., Werblow, A. (2004), "Population Ageing and Health Care Expenditure: New Evidence on the 'Red Herring'." Geneva Papers on Risk and Insurance, Vol. 29, No. 4. 